\title{
Case Report \\ Persistent Inflammation in Pulmonary Granuloma 48 Years after Talcage Pleurodesis, Detected by FDG-PET/CT
}

\author{
J. C. Fanggiday, ${ }^{1}$ R. W. Rouse, ${ }^{2}$ S. M. Collard, ${ }^{3}$ M. J. de Haas, ${ }^{1}$ and J. M. H. de Klerk ${ }^{1}$ \\ ${ }^{1}$ Department of Nuclear Medicine, Meander Medical Center, Utrechtseweg 160, \\ 3818 ES Amersfoort, The Netherlands \\ ${ }^{2}$ Department of Pathology, Meander Medical Center, Utrechtseweg 160, \\ 3818 ES Amersfoort, The Netherlands \\ ${ }^{3}$ Department of Pulmonology, Meander Medical Center, Utrechtseweg 160, 3818 ES Amersfoort, The Netherlands
}

Correspondence should be addressed to J. C. Fanggiday, jcfanggiday@gmail.com

Received 29 April 2012; Accepted 15 October 2012

Academic Editor: S. A. Sahn

Copyright (C) 2012 J. C. Fanggiday et al. This is an open access article distributed under the Creative Commons Attribution License, which permits unrestricted use, distribution, and reproduction in any medium, provided the original work is properly cited.

In patients with suspicion of lung malignancy, FDG PET/CT is frequently used as a diagnostic and staging imaging modality. However, false positive findings are not uncommon. We demonstrate a case with FDG-avid pulmonary nodules, mimicking lung cancer. After histopathological examination they appeared to be the result of persistent inflamed tissue, due to talcage pleurodesis, which occurred 48 years ago. We concluded that, nearly five decades after talcage pleurodesis, there can still be an ongoing inflammation reaction in the pleurae, which can be detected by FDG PET/CT.

\section{Case Report}

A 68-year-old male, nonsmoker, visited the outpatient clinic of the urologist. He is known with a carcinoma of the prostate, cT1c Gleason score 6, tumour-load less than 10\%, right sided. Abdominal CT revealed no signs of lymphogenous or distant metastasis. Transrectal ultrasonography and clinical evaluation showed no signs of local invasion, so a strategy of active surveillance has been proposed. Further medical history revealed a spontaneous left-sided pneumothorax, treated with talcage pleurodesis at the age of 20 . There were no asbestos exposure, no known exposure of tuberculosis.

After a period of cough, chest radiography has been performed, which showed nodular structures, subpleural in the left upper lobe and just lateral of the thoracic aorta. The patient was sent by the general practitioner to the pulmonologist and due to his medical history and the result of the chest radiography an FDG-PET/CT has been made.

Computed tomography showed indeed a round, dense structure ventral in the left upper lobe, with an $\mathrm{HU}$ value of 168 (Figure 1). The paraaortic nodule revealed an HU value of 132 (Figure 2). All these nodules showed a high FDG uptake, with respectively maximum standard uptake values (SUVmax) of 16.4 and 7.7. At some places the pleurae appeared to be thickened and hyperdense at CT, with also high FDG uptake (SUV max 4.7). No abnormalities elsewhere were observed, especially no hilar or mediastinal lymphadenopathy. No signs of emphysema.

Patient underwent a video assisted thoracoscopy. The upper lobe appeared to be stitched with the mediastinal wall. The ventral nodule was localized and excised. Pathology showed a nodule mainly consisting of lung and pleural tissue, and furthermore, multinucleated foreign-body giant cells and histiocytes reaction with many birefringent crystals. No signs of malignancy (Figures 3, 4, and 5) were observed. This is in accordance with a foreign-body reaction with ongoing inflammation.

The paraaortic nodule has not been excided. However, follow-up FDG-PET/CT scan after half a year showed no changes in CT and FDG-PET characteristics of this nodule. 


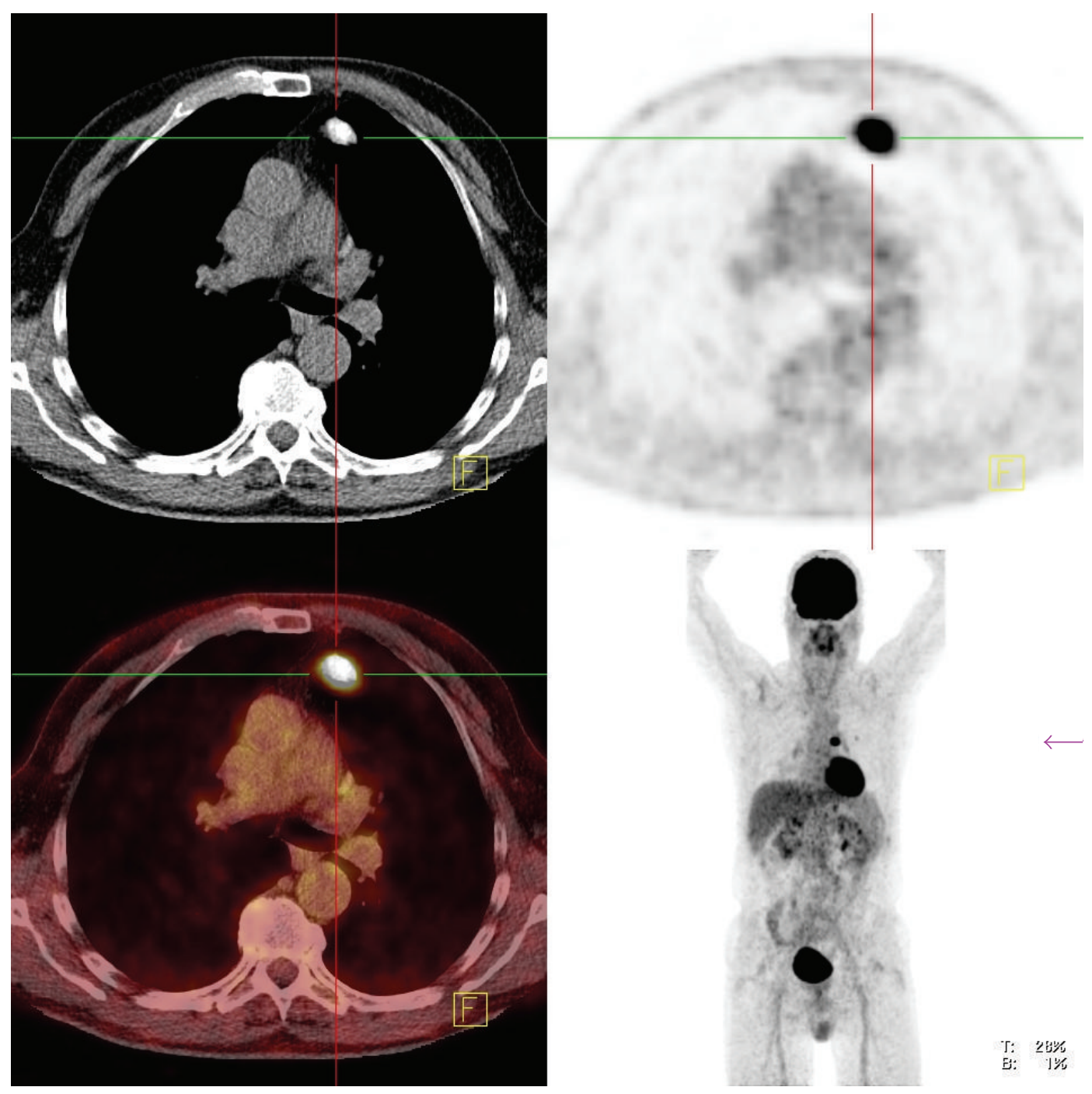

FIgURE 1: Pulmonary nodule with high FDG uptake ventrally in the left upper lobe.

\section{Discussion}

Since the introduction of talc pleurodesis by Bethune in 1935, this procedure is used to manage recurrent malignant and nonmalignant pleural effusions and recurrent or persistent pneumothoraces [1]. Talc is hydrated magnesium silicate and causes an intrapleural inflammatory response. Adhesion molecules, cytokines IL-8, VEGF, and TGF-beta are formed. This response is thought to cause adhesions [2, 3]. In 1969, Jones already described the effect of talcage pleurodesis, where as early as three weeks after the procedure talc granulomata were present [4].

Talc pleurodesis has proven its role in treatment of pneumothoraces [5]. There are no or minimal long-term side effects in these patients [6, 7]. Computed tomography appearances of talc pleurodesis are well described $[8,9]$. Results of talc pleurodesis can be seen at CT examination as lesions with high attenuation, in or nearby the pleurae.
Murray also hypothesized the FDG uptake in these lesions with granulomatous inflammation. In his series, FDG uptake was seen up to 10 months after pleurodesis [10]. Since that report, several authors described the FDG-PET appearances of talc pleurodesis. During followup, standard uptake values appeared to persist or increase further [11]. Several case reports described an increased FDG uptake, even years after initial talc pleurodesis. Peek et al. for example, described increased FDG uptake 10 and 11 years, respectively, after talc pleurodesis. Follow up was done without histological proof, but by CT, which showed no signs of malignancy after 16 months [12].

In our case both CT and FDG-PET findings fitted well with the characteristics described above. However, such a long interval after talcage biopsy with histologically proven diagnosis, to the best of our knowledge, has not been described before. 


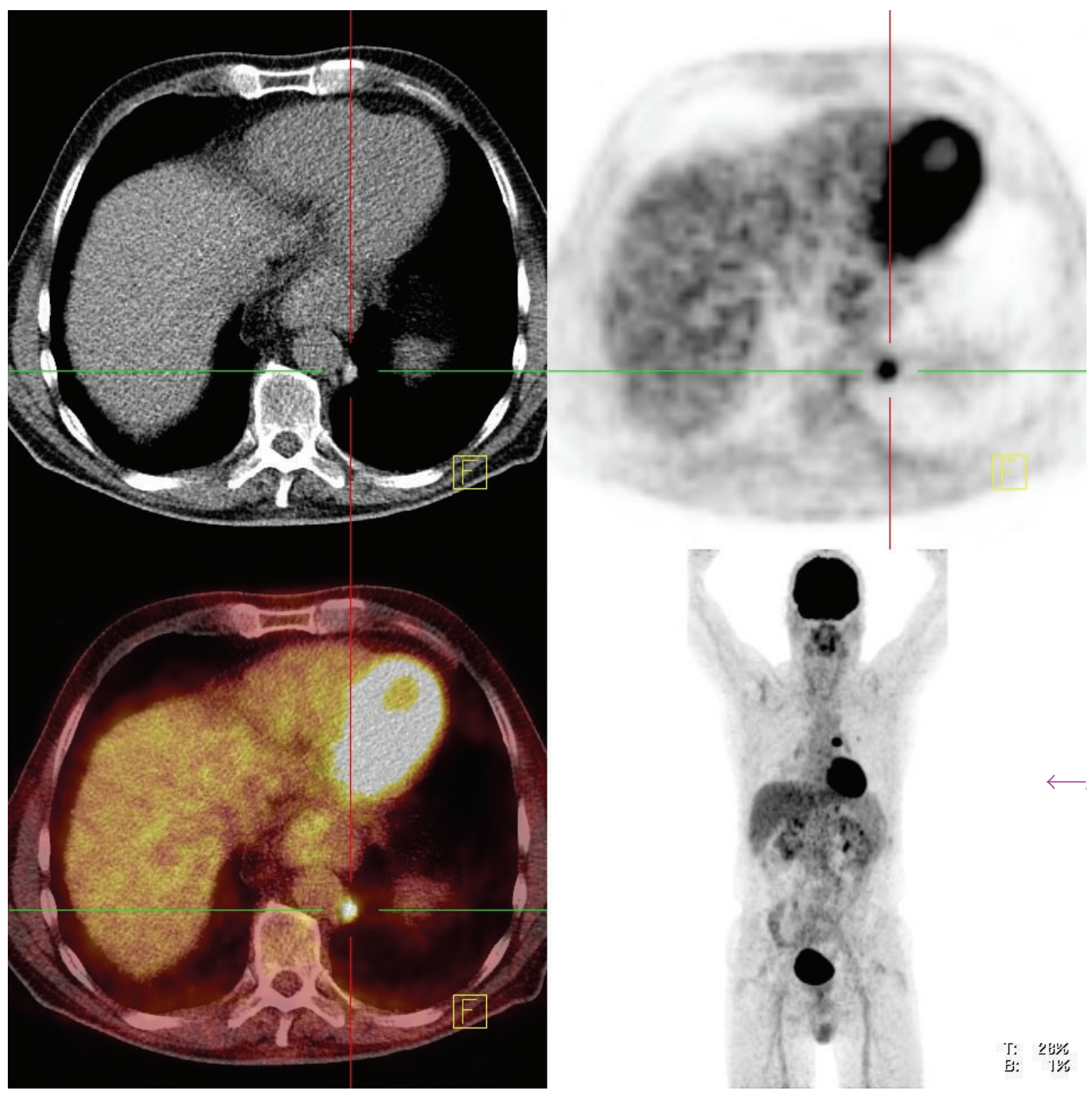

FIGURE 2: FDG-avid paraaortic nodal structure.

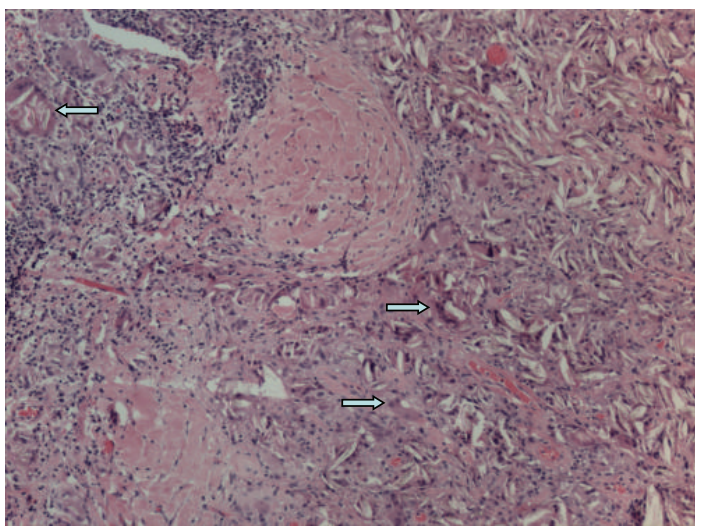

Figure 3: A representative low-power $(\mathrm{H} \& \mathrm{E}, \times 200)$ photograph showing crystals surrounded by multinucleated foreign-body giant cells (arrows). 


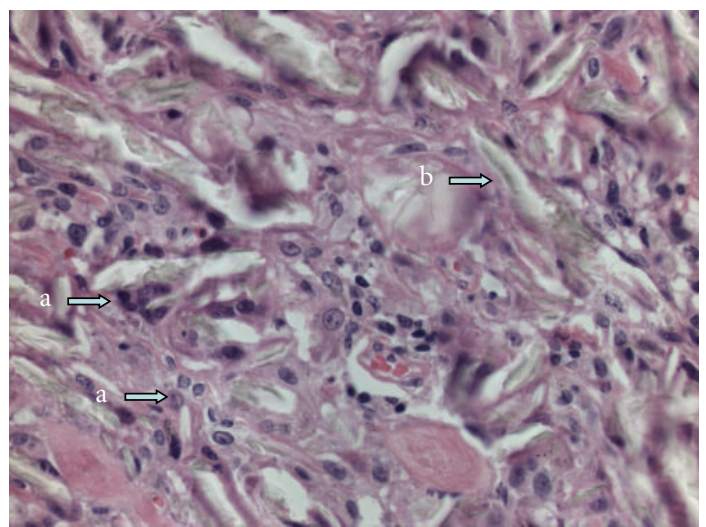

Figure 4: High-power view $(\mathrm{H} \& \mathrm{E}, \times 400)$ of Figure 3 , showing multinucleated foreign-body giant cells (a) and crystals (b).

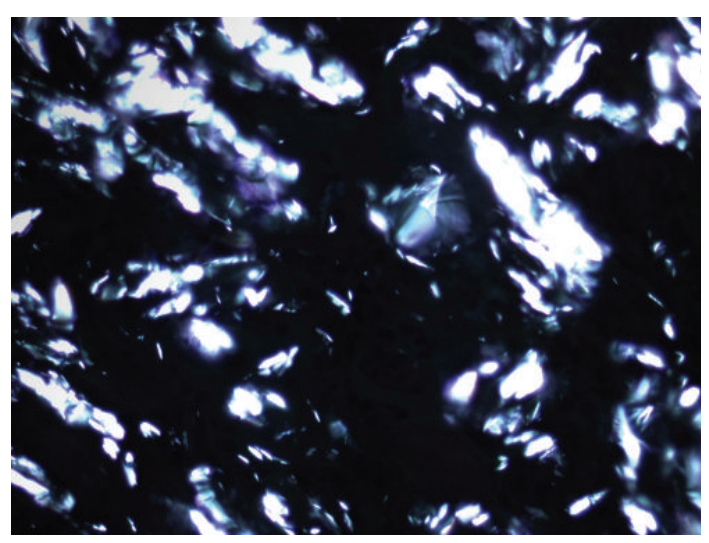

Figure 5: High-power view $(\mathrm{H} \& \mathrm{E}, \times 400)$ of polarized light microscopy of Figure 3, showing the birefringent characteristics of the crystals.

\section{Conclusion}

Pulmonary FDG-avid nodules due to talcage pleurodesis can occur even after almost fifty years after the procedure.

\section{References}

[1] N. Bethune, "Pleural poudrage: new technique for the deliberate production of pleural adhesion as preliminary to lobectomy," Journal of Thoracic Surgery, vol. 4, p. 251, 1935.

[2] E. H. Genofre, E. Marchi, and F. S. Vargas, "Inflammation and clinical repercussions of pleurodesis induced by intrapleural talc administration," Clinics, vol. 62, no. 5, pp. 627-634, 2007.

[3] J. Ferrer, M. A. Villarino, J. M. Tura, A. Traveria, and R. W. Light, "Talc preparations used for pleurodesis vary markedly from one preparation to another," Chest, vol. 119, no. 6, pp. 1901-1905, 2001.

[4] G. R. Jones, "Treatment of recurrent malignant pleural effusion by iodized talc pleurodesis," Thorax, vol. 24, no. 1, pp. 69-73, 1969.

[5] L. Kennedy and S. A. Sahn, "Talc pleurodesis for the treatment of pneumothorax and pleural effusion," Chest, vol. 106, no. 4, pp. 1215-1222, 1994.
[6] I. Hunt, B. Barber, R. Southon, and T. Treasure, "Is talc pleurodesis safe for young patients following primary spontaneous pneumothorax?" Interactive Cardiovascular and Thoracic Surgery, vol. 6, no. 1, pp. 117-120, 2007.

[7] S. Györik, S. Erni, U. Studler, R. Hodek-Wuerz, M. Tamm, and P. N. Chhajed, "Long-term follow-up of thoracoscopic talc pleurodesis for primary spontaneous pneumothorax," European Respiratory Journal, vol. 29, no. 4, pp. 757-760, 2007.

[8] S. Narayanaswamy, S. Kamath, and M. Williams, "CT appearances of talc pleurodesis," Clinical Radiology, vol. 62, no. 3, pp. 233-237, 2007.

[9] J. G. Murray, E. F. Patz, J. J. Erasmus, and R. C. Gilkeson, “CT appearance of the pleural space after talc pleurodesis," American Journal of Roentgenology, vol. 169, no. 1, pp. 89-91, 1997.

[10] J. G. Murray, J. J. Erasmus, E. A. Bahtiarian, and P. C. Goodman, "Talc pleurodesis simulating pleural metastases on $18 \mathrm{~F}-$ fluorodeoxyglucose positron emission tomography," American Journal of Roentgenology, vol. 168, no. 2, pp. 359-360, 1997.

[11] N. C. Nguyen, I. Tran, C. N. Hueser, D. Oliver, H. R. Farghaly, and M. M. Osman, "F-18 FDG PET/CT characterization of talc pleurodesis-induced pleural changes over time: a retrospective study," Clinical Nuclear Medicine, vol. 34, no. 12, pp. 886-890, 2009.

[12] H. Peek, W. van der Bruggen, and G. Limonard, "Pleural FDG uptake more than a decade after talc pleurodesis," Case Reports in Medicine, vol. 2009, Article ID 650864, 3 pages, 2009. 


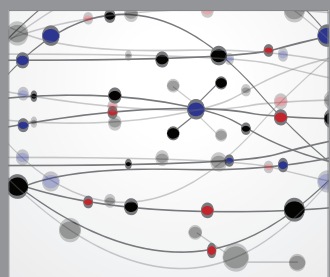

The Scientific World Journal
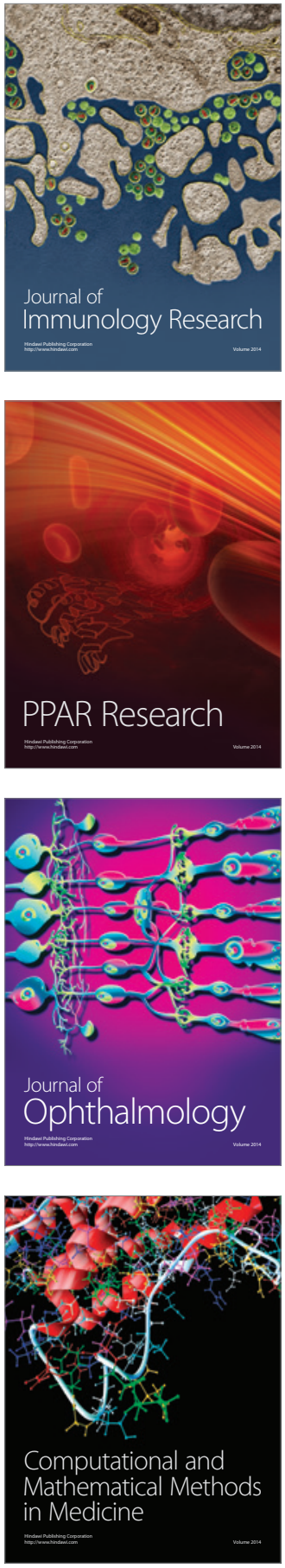

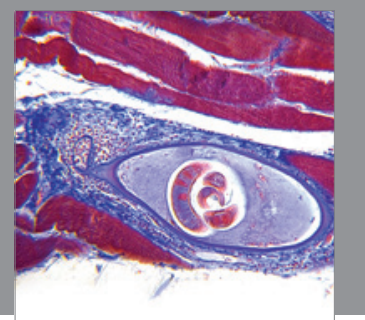

Gastroenterology

Research and Practice
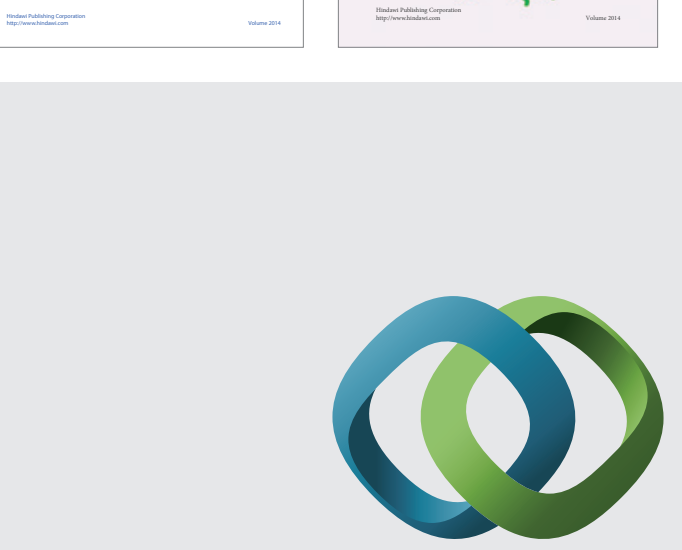

\section{Hindawi}

Submit your manuscripts at

http://www.hindawi.com
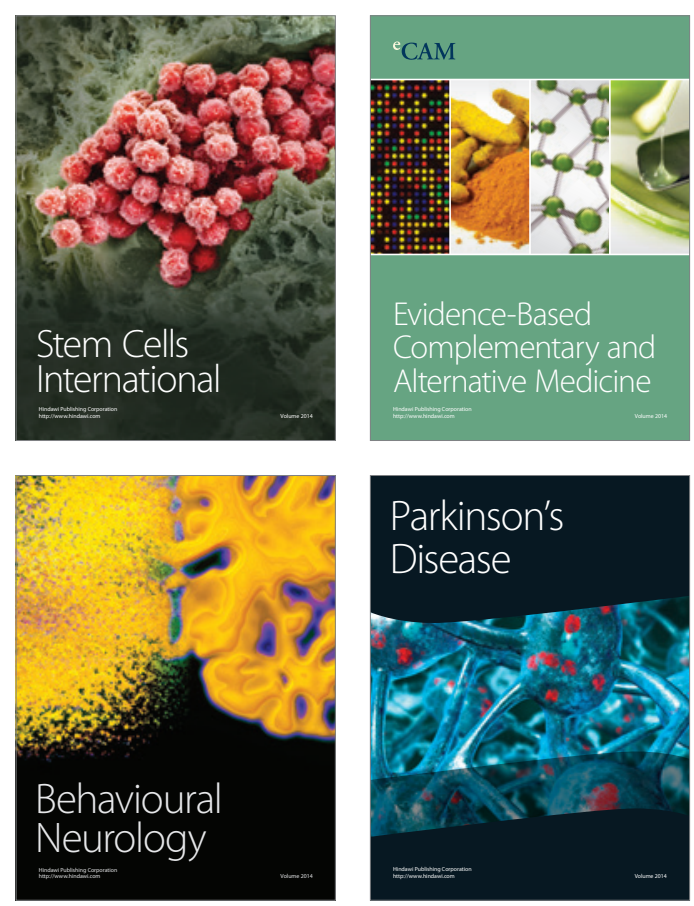

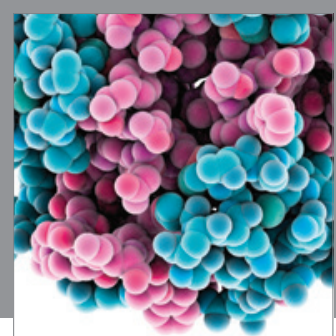

Journal of
Diabetes Research

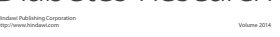

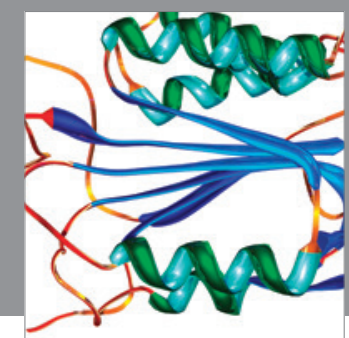

Disease Markers
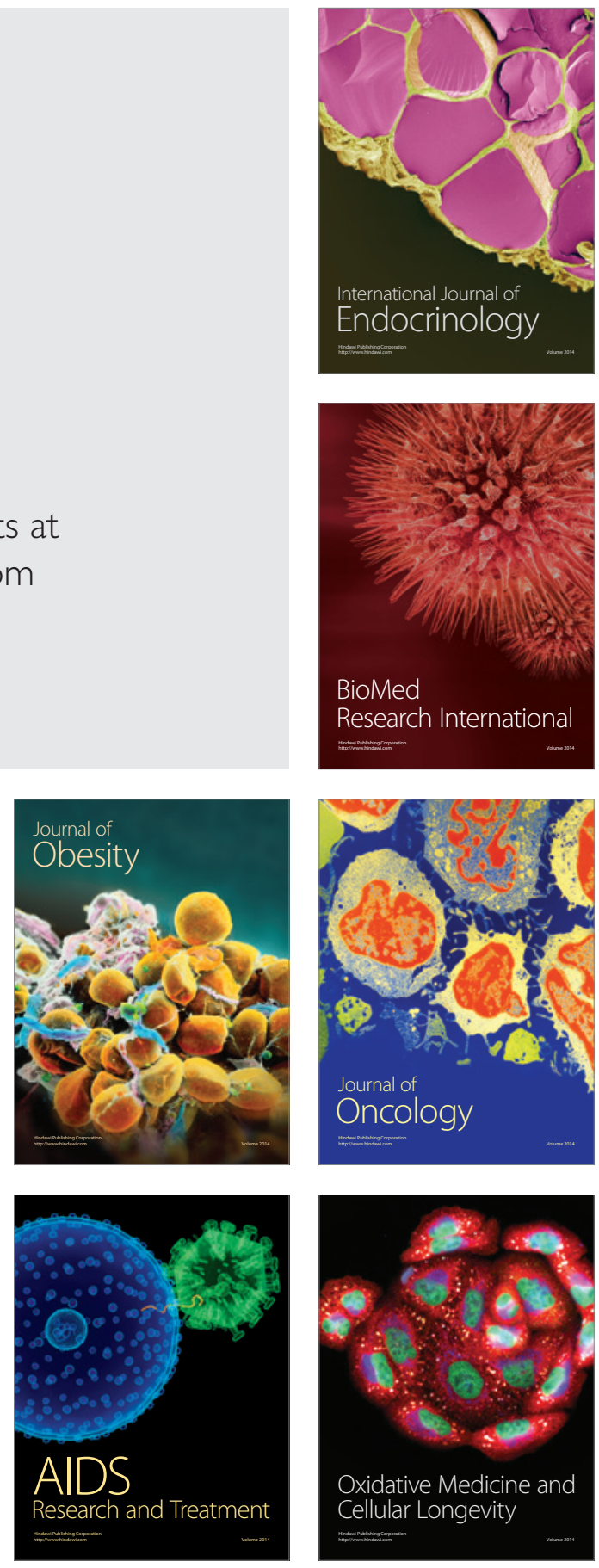